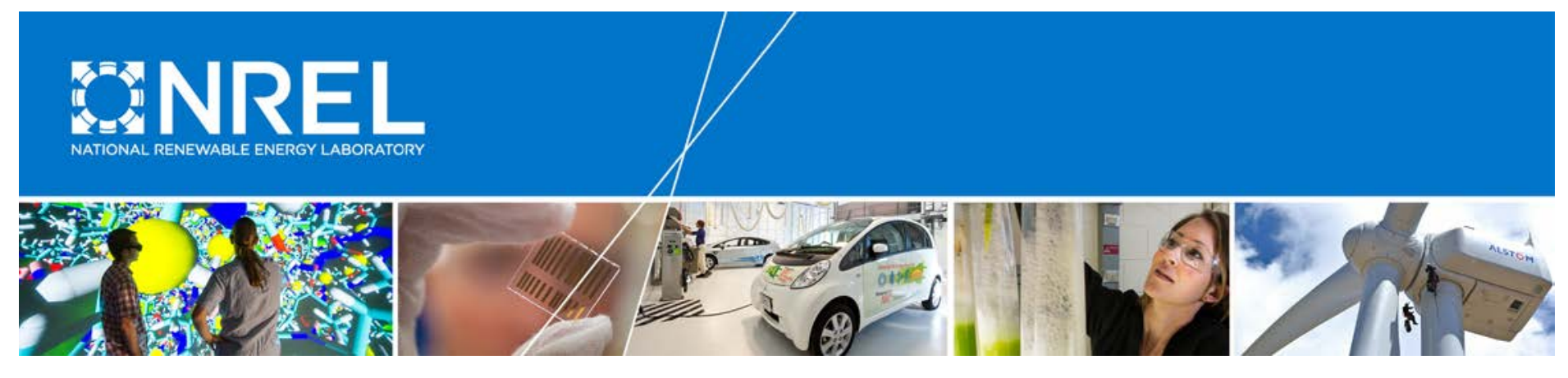

\title{
Estimate of Fuel Consumption and GHG Emission Impact on an Automated Mobility District
}

\section{Preprint}

Yuche Chen, Stanley Young, and Jeff Gonder National Renewable Energy Laboratory

Xuewei Qi

University of California Riverside

Presented at the 4th International Conference on Connected Vehicles \& Expo (ICCVE 2015)

Shenzhen, China

October 19-23, 2015

NREL is a national laboratory of the U.S. Department of Energy Office of Energy Efficiency \& Renewable Energy Operated by the Alliance for Sustainable Energy, LLC

This report is available at no cost from the National Renewable Energy Laboratory (NREL) at www.nrel.gov/publications.

Conference Paper

NREL/CP-5400-65257

December 2015

Contract No. DE-AC36-08GO28308 


\section{NOTICE}

The submitted manuscript has been offered by an employee of the Alliance for Sustainable Energy, LLC (Alliance), a contractor of the US Government under Contract No. DE-AC36-08GO28308. Accordingly, the US Government and Alliance retain a nonexclusive royalty-free license to publish or reproduce the published form of this contribution, or allow others to do so, for US Government purposes.

This report was prepared as an account of work sponsored by an agency of the United States government. Neither the United States government nor any agency thereof, nor any of their employees, makes any warranty, express or implied, or assumes any legal liability or responsibility for the accuracy, completeness, or usefulness of any information, apparatus, product, or process disclosed, or represents that its use would not infringe privately owned rights. Reference herein to any specific commercial product, process, or service by trade name, trademark, manufacturer, or otherwise does not necessarily constitute or imply its endorsement, recommendation, or favoring by the United States government or any agency thereof. The views and opinions of authors expressed herein do not necessarily state or reflect those of the United States government or any agency thereof.

This report is available at no cost from the National Renewable Energy Laboratory (NREL) at www.nrel.gov/publications.

Available electronically at SciTech Connect http:/www.osti.gov/scitech

Available for a processing fee to U.S. Department of Energy and its contractors, in paper, from:

U.S. Department of Energy

Office of Scientific and Technical Information

P.O. Box 62

Oak Ridge, TN 37831-0062

OSTI http://www.osti.gov

Phone: 865.576.8401

Fax: 865.576.5728

Email: reports@osti.gov

Available for sale to the public, in paper, from:

U.S. Department of Commerce

National Technical Information Service

5301 Shawnee Road

Alexandria, VA 22312

NTIS http://www.ntis.gov

Phone: 800.553 .6847 or 703.605 .6000

Fax: 703.605.6900

Email: orders@ntis.gov 


\title{
Estimate of Fuel Consumption and GHG Emission Impact from an Automated Mobility District
}

\author{
Yuche Chen, Stanley Young, Xuewei Qi, IEEE, Student Member, Jeffrey Gonder
}

\begin{abstract}
This study estimates the range of fuel and emissions impacts of an automated-vehicle (AV)-based transit system that services campus-based developments, termed an automated mobility district (AMD). The study develops a framework to quantify the fuel consumption and greenhouse gas (GHG) emission impacts of a transit system comprised of AVs, taking into consideration average vehicle fleet composition, fuel consumption/GHG emission of vehicles within specific speed bins, and the average occupancy of passenger vehicles and transit vehicles. The framework is exercised using a previous mobility analysis of a personal rapid transit (PRT) system, a system that shares many attributes with envisioned AVbased transit systems. Total fuel consumption and GHG emissions with and without an AMD are estimated, providing a range of potential system impacts on sustainability. The results of a previous case study based on a proposed implementation of PRT on the Kansas State University (KSU) campus in Manhattan, Kansas, serve as the basis for estimating personal miles traveled supplanted by an AMD at varying levels of service. The results show that an AMD has the potential to reduce total system fuel consumption and GHG emissions, but the amount is largely dependent on operating and ridership assumptions. The study points to the need to better understand ridesharing scenarios and calls for future research on sustainability benefits of an AMD system at both vehicle and system levels.
\end{abstract}

Keywords-Automated vehicles, mobility district, energy analysis

\section{INTRODUCTION}

Automated mobility district (AMD) is introduced as a term to describe a campus-size implementation of automated/ connected vehicle technology to realize the benefits of a fully

Yuche Chen, Stanley Young, and Jeffrey Gonder are with the National Renewable Energy Laboratory, Golden, CO 80401, USA. Xuewei Qi is with the Department of Electrical and Computer Engineering, University of California Riverside, Riverside, CA 92521, USA. Email: Yuche.Chen@nrel.gov, Stanley.Young@nrel.gov, xqi001@ucr.edu, Jeff.Gonder@nrel.gov. automated vehicle mobility service. AMD is closely related to the past concepts of personal rapid transit (PRT) and group rapid transit (GRT) studied and implemented in the 1970s, with the primary difference being that PRT and GRT are captive to a guideway as opposed to running on the existing roadway infrastructure. In the past decade, the term automated transit network (ATN) was coined and refers to largely the same concept, including both PRT and GRT, but broader in technical scope to reflect a wider array of automation technology that may allow the system to use existing infrastructure rather than a completely dedicated guideway. An ATN remains primarily the same service concept as PRT and GRT and the envisioned AMD with AVs. All are characterized by driverless, on-demand transit that provides direct origin-todestination service to either individuals or small groups. Although AMD can be realized (and has been implemented) with PRT, GRT, and ATN systems on dedicated guideways, current AV-based reasoning envisions a system of automated taxis controlled and dispatched within a limited geographic area and utilizing existing roadway infrastructure. A typical AMD system may have the following basic features:

1) Fully automated and driverless vehicles. A National Highway Traffic Safety Administration level 4 or SAE level 5 vehicle capable of all safety-critical driving functions and able to monitor roadway conditions and pilot a vehicle for an entire trip [1,2]. Such a design anticipates that the passenger will provide destination input, but is not expected to be available for vehicle control at any time during the trip.

2) Service is confined to a geographic boundary that encompasses a relatively dense area of trip attractions, such as a campus area. This may be a medical, academic, or business park, or any other type of campus. Such areas are typified by jobs, attractions, and other activities that draw people on a daily basis. Although residential land use is not prohibited, it is not the dominant land use within such a district. The geographic extent is limited, typically to 4 to 10 square miles.

3) Mobility within the district is restricted to or dominated by the AMD. Within the district, access to end destinations is provided by automated vehicle service. Personal vehicles may or may not be prohibited, but at a minimum, the area is designed to be most efficiently accessed by the AMD, although other forms may be permitted. 
4) Multi-modal access to the perimeter of the area (the cordon line or membrane of the AMD) provides efficient opportunity for modal interface to the AMD, through bus, light-rail, or other modes. This may include ample parking for people to transfer from personal vehicles to the AMD to reach their final destination.

The challenges to provide efficient mobility to such campuses include:

1) Amount and proximity of parking: Many such campuses are primarily accessed by private automobile today even when other transit options are present. The quantity, quality, and proximity of parking become policy issues, not only for mobility, but also for policies that touch on benefits and compensation (e.g., reserved and named parking). The search for parking frequently contributes to vehicle miles traveled (VMT) within the campus and in vehicle-pedestrian congestion.

2) Effective intra-campus circulation: The geographic expanse of campuses of this size make walking impractical for most intra-campus circulation, because the majority of such trips will be greater than a quarter mile, a frequently used maximum boundary for pedestrian activity. Although many campuses have traditional shuttle service, its frequency and quality often prompt users to use personal vehicles to relocate within the campus if possible.

3) Pedestrian-vehicle conflict and congestion: Academic campuses may limit or fully prohibit vehicle circulation within the campus boundaries to maintain an attractive pedestrian environment. As campuses grow, demands of efficient exterior access via automobile conflict with intracampus pedestrian movement, creating less than desirable conflicts for both modes and introducing safety concerns primarily for pedestrians and cyclists.

4) Efficient access by transit and service vehicles: Medical, academic, recreation, and other campuses typically encourage, and some require, their clientele to access campus facilities using non-personal vehicle methods. Public buses, private shuttles, line-haul systems (rail and light-rail), ambulances, ride-hailing (e.g., Uber, Lyft), all provide options, but without an efficient intra-campus mobility system, such systems fail to provide full and efficient service to patrons for all campus destinations, and for intra-campus trips.

An AMD is conceived to address many of the issues above. In a previous work dating from 2003 [3, 4], the mobility benefits of a PRT system to serve the Kansas State University (KSU) main campus in Manhattan, Kansas, was studied to address similar issues. The study quantified the mobility impact of a PRT system on access to and circulation within the campus. Based on trip data available from various university departments, the study modeled the travel demand within and around a university campus. Trip assignment spanned multiple modes, including driving, walking, parking, and riding a proposed PRT system. The KSU study modeled and contrasted traffic flow patterns for the existing system of transportation and various proposed future alternatives, documenting the potential mobility benefits and impacts of various level of PRT service implemented within a university setting. The quantitative results included the quantity of personal miles traveled (PMT) by vehicle supplanted by automated system travel due to the introduction of the PRT system. The transfer of PMT between personal vehicles and the PRT system was primarily interior to the campus consistent with the geographic extents of the proposed PRT system. Only pedestrian and personal vehicle modes were modeled to provide access to the campus from nodes outside the campus (no traditional transit service), which was reflective of campus transportation at $\mathrm{KSU}$ at the time of the study.

The study revealed that a PRT system would increase total PMT. With a PRT system, PMT from personal vehicles were supplanted by PMT on the PRT. The reduction in PMT from personal vehicles and subsequent increase in PMT on the PRT were a function of the operational parameters of the PRT system. As the PRT system utilized more vehicles such that the delay time to access the system was reduced (from 6 minutes to 3 minutes to 2 minutes), the quantity of PMT supplanted by the PRT increased proportionally. These results indicated that a properly designed AMD can reduce vehicle PMT within campus, transferring PMT from personal vehicles to the AMD system. Note the induced PMT on the AMD was greater than the reduced PMT of personal vehicles. The reduction or increase of energy and greenhouse gases (GHG) is thus a function of the difference in vehicle characteristics (type of fuel and drivetrain), system characteristics (vehicle occupancy, speed, and amount of empty vehicle circulation), and ratio of supplanted PMT between personally driven vehicles and those of vehicles within an AMD.

The KSU study also provided an analysis of various mobility benefits such as reduction in travel time, increase in travel time reliability, and better parking management. The campus PRT system saves an average of $10 \%$ travel time for each user on the door-to-door commute trip to campus. The PRT significantly increases travel time reliability by eliminating inefficient intra-campus travel searching for parking. More than $18 \%$ of the trips generated in the study area included PRT as part of the route in the most responsive PRT configuration, which required patrons to wait a maximum of two minutes [3, 4]. Although the mobility benefits are critical for system acceptance, this study is focused in sustainability benefits as a function of AMD vehicles and system attributes in contrast to personal vehicles.

\section{BACKGROUND}

\section{A. Study Site Description}

The city of Manhattan, Kansas (as it existed at the time of the original study), was the study area for this project. The main KSU campus and the surrounding community were selected as the impact area. The broad area that is beyond the Manhattan city limits and the KSU main campus was treated as external areas (implemented as external nodes in the modeling process).

The Manhattan community encompasses approximately 11 square miles and had a population of 44,800 (in 2001). A map of Manhattan is shown in Fig. 1. 


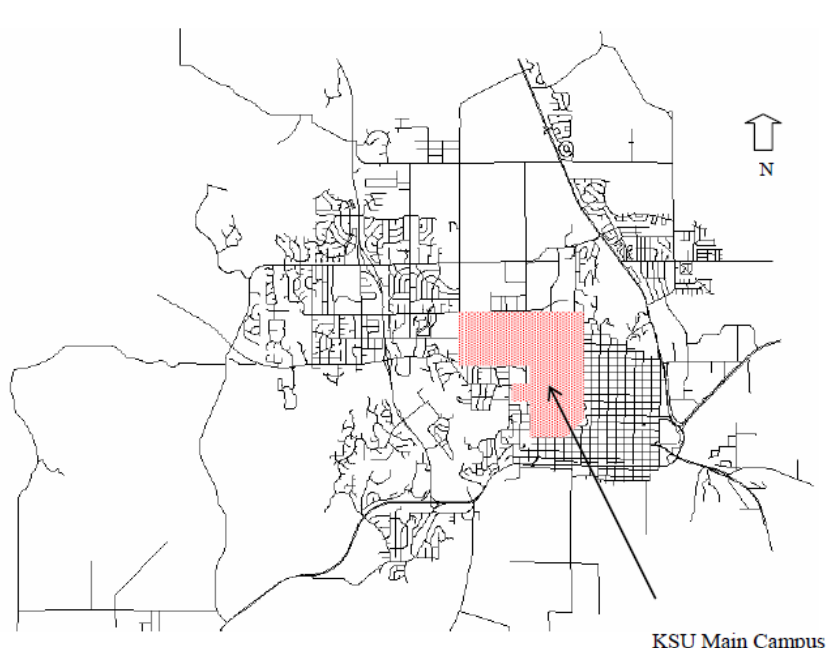

Fig. 1 Street map of Manhattan, Kansas [3].

KSU is a comprehensive research land-grant institution. The KSU main campus has a land area of 664 acres. The total student population enrolled (on campus only) in Fall 2001 was 21,929. The total faculty/staff number (full-time employees only) in Fall 2001 was approximately 2,200. The KSU population, including students, faculty, and staff, amounts to approximately $50 \%$ of the population of Manhattan. Fig. 2 shows a map of the KSU main campus.

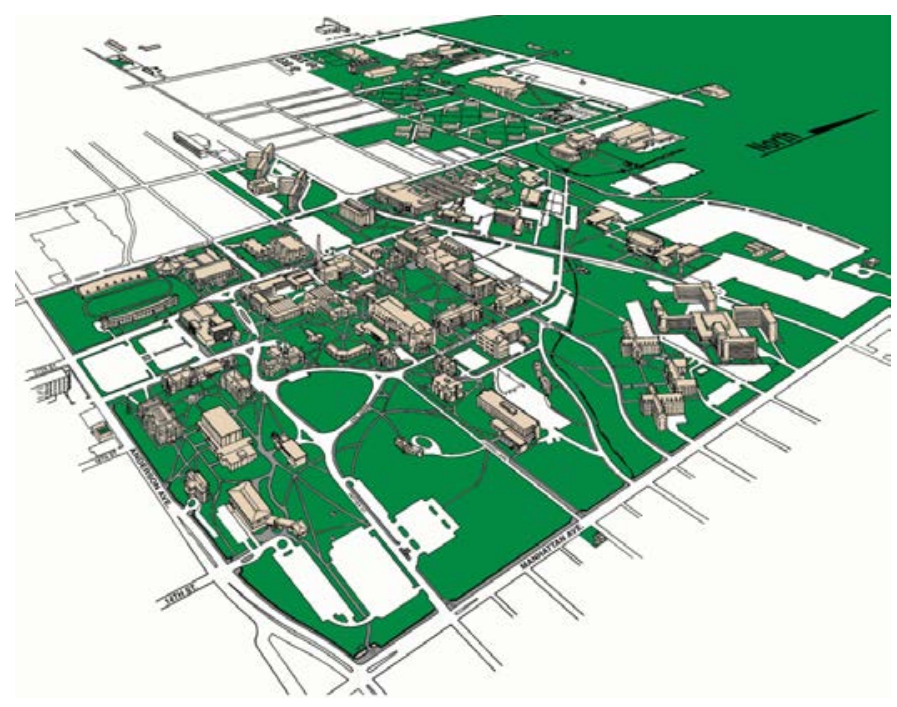

Fig. 2. Map of the KSU main campus [3]

\section{B. Personal Rapid Transit}

Although the definition of a PRT system varies in literature, the Advanced Transit Association [5] adopted a set of guidelines as presented in Table 1 for PRT characteristics. The description in Table 1 supports the hypothesis that the PRT service delivery is analogous to currently envisioned automated taxi AMD concepts and thus can serve as an initial estimate of both mobility impacts as well as sustainability impacts.

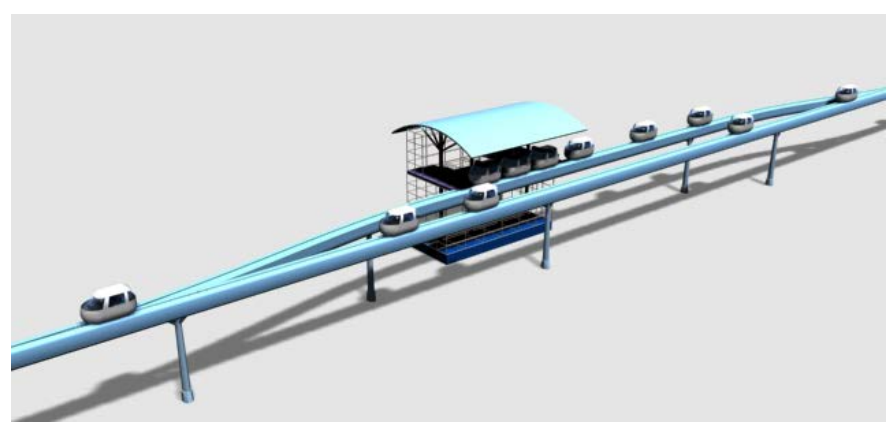

Fig. 3. A PRT station design [4].

TABLE 1. ESSENTIAL CHARACTERISTICS OF A STANDARD PRT SYSTEM

Category Characteristics

Vehicles 1. Fully automated-no human drivers.

2. Captive to the guideway.

3. Available for exclusive use by an individual or small groups traveling together by choice.

4. All vehicles are able to use all guideways and stations on a fully connected PRT network.

\begin{tabular}{ll}
\hline Guideways & 1. Exclusive use by only PRT vehicles. \\
& 2. Small in size and weight. \\
& $\begin{array}{l}\text { 3. Can be elevated, on the ground, or } \\
\text { underground. }\end{array}$ \\
\hline Service & 1. 24 hours a day. \\
& $\begin{array}{l}\text { 2. Direct origin-to-destination, with no necessity } \\
\text { to transfer or stop at intervening stations. } \\
\text { 3. Available on demand rather than on fixed } \\
\text { schedules. }\end{array}$
\end{tabular}

Source: The Advanced Transit Association, 1988 [5].

\section{MethodOLOGY}

The original PRT study's focus was on improvements in mobility as measured by metrics such as travel time, reliability, and isochronal access maps [3]. This second phase of analysis, prompted by energy and GHG concerns, assesses the sustainability benefits of a PRT system in a campus environment. This analysis serves as a surrogate to estimate sustainability impacts of envisioned AMD systems enabled through AV technology. The PRT, GRT, and ATN mobility concepts studied from 1970 through today reflect similar service attributes as AV-enabled AMD, differing primarily by the use of a dedicated guideway rather than use of existing roadways. The extension of the 2003 PRT mobility analysis serves also to identify critical issues for further modeling and simulation in future research of AMDs.

The framework for estimating energy and GHG impacts is based on likely vehicle characteristics and system configurations. Powertrain and fuel consumption characteristics of existing vehicle fleets and projected electrified vehicles serve as the basis for vehicle emission estimates. Private vehicle occupancy statistics and ride-sharing characteristics of PRT systems (including empty vehicle circulation) likewise form the basis for calculating VMT from PMT. 


\section{A. Mobility Analysis}

In the Young et al. study, the mobility benefits of installing a PRT system on the campus site were analyzed with results shown in Table 2 [3] for the diversion of travel between various modes as a function of varying PRT service. These results were obtained from a modified four-step modeling process in which the mode and route choice from origin to destination was determined by travel time.

The classic four-step modeling process consists of trip generation, trip distribution, mode choice, and route assignment. The modifications to enable modeling the impact of PRT included the following:

- $\quad$ The modeled network included roads, sidewalks, parking facilities, the PRT network, and all interconnections. Each traveler chose the route through the system that minimized overall travel time. The final link to any University destination was via a sidewalk link.

- $\quad$ The PRT network was only accessible via sidewalk links. Various levels of responsiveness of the PRT system were modeled with differing fixed wait times for service.

- $\quad$ Parking was modeled as a segment bridging roadways to sidewalks with a delay function that was dependent on the lot's volume to occupancy ratio, and the traveler's parking permit classification.

- Rather than travel mode being a discrete, mutually exclusive choice, route choice was determined by the portion of each trip spent on each mode.

- The trip matrix was compiled from the University line schedule and staff/student database (confidentiality maintained) and augmented with a gravity model for nonUniversity or non-class related trips.

\section{B. Energy and GHG Analysis}

The trip table implemented in the model reflects the patterns of students and staff accessing the campus for classes and employment for a typical weekday. The reader is referred to [3] for further details on model construction. The top level results of personal miles traveled (PMT) on various modes for the four scenarios exhibited in Table 2 form the basis for the follow-on energy and GHG analysis.

Based on the mobility results in Table 2, the reductions or increases of personal miles traveled per day (PMTD) and personal hours traveled per day (PHTD) are calculated (Table 3 ). The results show that the introduction of a PRT system reduces PMTD and PHTD for travel on the roadway network and sidewalk network. Additionally, as PRT service becomes more responsive (as noted by decreasing delay times), it induces ever greater reductions in road and sidewalk PMTD and PHTD compared with the base scenario. Note that, in Table 2, the PHTD on parking lot includes both vehicle traveling time and pedestrian walking time. There was insufficient detail in the original study to sub-divide parking delay between vehicle travel and pedestrian. This study assumes all PHTD within parking lots are associated vehicle travel time, providing a maximum estimate of fuel expenditures accessing parking.
TABLE 2. BASE LEVEL RESULTS FOR PRT NETWORK [3]

\begin{tabular}{|c|c|c|c|c|}
\hline \multirow[b]{2}{*}{$\begin{array}{l}\text { Person Miles } \\
\text { Traveled per Day }\end{array}$} & \multirow{2}{*}{$\begin{array}{c}\begin{array}{c}\text { Base } \\
\text { Scenario }\end{array} \\
\text { No PRT }\end{array}$} & \multicolumn{3}{|c|}{ PRT Delay Scenarios } \\
\hline & & $6 \mathrm{Min}$ & $3 \mathrm{Min}$ & $2 \mathrm{Min}$ \\
\hline $\begin{array}{l}\text { Driving on the } \\
\text { Road Network }\end{array}$ & 40,131 & 38,352 & 36,621 & 35,807 \\
\hline $\begin{array}{l}\text { Walking on the } \\
\text { Sidewalks }\end{array}$ & 20,216 & 18,814 & 16,770 & 15,681 \\
\hline Riding the PRT & 0 & 3,604 & 8,169 & 10,279 \\
\hline Total & 60,347 & 60,770 & 61,560 & 61,767 \\
\hline $\begin{array}{l}\text { Person Hours } \\
\text { Traveled per Day }\end{array}$ & No PRT & $6 \mathrm{Min}$ & $3 \mathrm{Min}$ & 2 Min \\
\hline $\begin{array}{l}\text { Driving on the } \\
\text { Road Network }\end{array}$ & 2,014 & 1,927 & 1,842 & 1,805 \\
\hline $\begin{array}{l}\text { Walking on the } \\
\text { Sidewalks }\end{array}$ & 5,037 & 4,688 & 4,186 & 3,923 \\
\hline In the Parking Lot & 1,877 & 1,686 & 1,532 & 1,497 \\
\hline Riding the PRT & 0 & 458.2 & 842.6 & 1,035 \\
\hline Total & 8,928 & $8,759.2$ & 8,403 & 8,260 \\
\hline
\end{tabular}

TABLE 3. REDUCTION OR INCREASE OF PMTD AND PHTD

\begin{tabular}{lllll}
\hline & $\begin{array}{l}\text { Base } \\
\text { Scenario }\end{array}$ & \multicolumn{3}{l}{ PRT Delay Scenarios } \\
\hline $\begin{array}{l}\text { Reduction/Increase of } \\
\text { daily PMT }\end{array}$ & No PRT & 6 Min & 3 Min & 2 Min \\
\hline $\begin{array}{l}\text { Driving on the Road } \\
\text { Network }\end{array}$ & - & $-1,779$ & $-3,510$ & $-4,324$ \\
\hline $\begin{array}{l}\text { Walking on the } \\
\text { Sidewalks }\end{array}$ & - & $-1,402$ & $-3,446$ & $-4,535$ \\
\hline Riding the PRT & - & 3,604 & 8,169 & 10,279 \\
\hline Total & 0 & 423 & 1,213 & 1,420 \\
\hline $\begin{array}{l}\text { Reduction/Increase of } \\
\text { daily PHT }\end{array}$ & No PRT & 6 Min & 3 Min & 2 Min \\
\hline $\begin{array}{l}\text { Driving on the Road } \\
\text { Network }\end{array}$ & - & -87 & -172 & -209 \\
\hline $\begin{array}{l}\text { Walking on the } \\
\text { Sidewalks }\end{array}$ & - & -349 & -851 & $-1,114$ \\
\hline In the Parking Lot & - & -191 & -345 & -380 \\
\hline Riding the PRT & - & 458 & 843 & 1,035 \\
\hline Total & 0 & -168.8 & -525.4 & -668 \\
\hline \hline
\end{tabular}

Note that the trips beyond the urban limits were represented by external nodes at the boundary of the study area. As a result driving portions of trips beyond the city limit are not included in these results.

The travel demand study included slightly over 70,000 trips loaded onto the network. Under the base scenario the total travel distance per day (inside the urban boundary) was approximately 60,000 miles, 40,000 miles were driving on the 
road network, and 20,000 were walking. On a per trip basis in the base scenario, the average driving distance was 0.57 miles, and the average pedestrian walking distance was 0.29 miles. Under the base scenario the amount of time spent in parking facilities was 1,877 hours, or about 1.61 minutes per trip. This includes the time needed to search for a parking space, exit the vehicle, and walk to the sidewalk facility servicing the lot.

To estimate energy and GHG emission impacts of a PRT system, the analysis framework takes PMT and average occupancy on various modes as inputs and calculates energy consumption and GHG emission for each mode.

The mathematical formulation of calculating total system fuel consumption and GHG emission are shown in equations (1) and (2).

$$
\begin{aligned}
& F C=\sum_{\forall t} \sum_{\forall m} V M T_{t}^{m} \times\left(1+\gamma^{m}\right) \times \delta_{t}^{m}\left(\bar{v}_{t}^{m}\right) \\
& G H G=\sum_{\forall t} \sum_{\forall m} V M T_{t}^{m} \times\left(1+\gamma^{m}\right) \times \theta_{t}^{m}\left(\bar{v}_{t}^{m}\right)
\end{aligned}
$$

The definitions of the parameters are:

$t$ : set of vehicle types: $\mathrm{T}=\{\mathrm{CV}$ : conventional passenger vehicle, PRT: personal rapid transit (taken as representative of an AMD)\}

$\mathrm{m}$ : set of different travel modes: $\mathrm{M}=$ \{Driving: driving on road network; Parking: searching on parking lot, Transit: Taking PRT\}

$V M T_{t}^{m}:$ VMT of vehicle type $t$ and mode $m$.

$\gamma^{m}$ : The empty driving VMT multiplier for mode $m$, when $\mathrm{m}=$ Driving or Parking, $\gamma^{m}=0$; when $\mathrm{m}=$ Transit, $\gamma^{m}$ can take several values as specified in the scenario.

$\delta_{t}^{m}\left(\bar{v}_{t}^{m}\right)$ : The fuel consumption per mile of travel mode $\mathrm{m}$ vehicle type $t$ at speed $\bar{v}_{t}^{m}$.

$\theta_{t}^{m}\left(\bar{v}_{t}^{m}\right)$ : The carbon dioxide emissions per mile of travel mode $m$ vehicle type $\mathrm{t}$ at speed $\bar{v}_{t}^{m}$

Passenger vehicle driving VMT (i.e., VMT by driving personal vehicles on the public road network) is obtained by dividing passenger vehicle PMT by average occupancy. Passenger vehicle parking VMT is calculated by multiplying VHT by passenger vehicles in parking lots with average vehicle speed in parking lots. The PRT VMT is obtained by dividing PRT PMT by the average PRT occupancy and then multiplying by the empty VMT factor.

Fuel consumption per mile for a passenger vehicle at various average speeds is based on the passenger vehicle's fuel consumption performance in real-world driving conditions. For PRT, we assume the PRT's fuel consumption using a steady-state passenger vehicle's fuel consumption data.

The average speed for vehicles traveling on the road network is estimated by dividing PMT on the road network by PHT on the road network from Table 2, which is approximately $19.9 \mathrm{mph}$ in all scenarios. The PMT and PHT on the road network do not include miles traveled and time spent within parking lots, as parking was modeled as a modal interface between roads and sidewalks with varying delays. The network model employed in the KSU study assigned a time delay representative of searching for and accessing a parking space, but not speed or distance traveled. The driving speed within the parking lots was assumed to be $8 \mathrm{mph}$ in the study. The default speed for the PRT system is $30 \mathrm{mph}$ [4].

A PRT system (as well as any AMD based on AV technology) will also incur empty-vehicle VMT. An estimate of the maximum induced VMT as a result of empty vehicle circulation is obtained by calculating the full system VMT, and then applying an empty-driving VMT amplification factor. A factor of 1.0 implies that for every passenger-carrying mile of travel, an empty-vehicle mile is incurred, whereas a factor of 0.5 implies that a half mile of empty-vehicle circulation is incurred for every mile of passenger service VMT incurred. For a passenger vehicle, the factor is set to be 0 .

The baseline study assumes that PRT vehicles are gasoline vehicles, but they could also be hybrid electric vehicles, plugin hybrid electric vehicles, or battery electric vehicles.

To support the implementation of the framework, other than the information from Young et al. [3], a literature search provided the following input data:

- Average occupancy: Average occupancy for passenger vehicles and PRT are needed. The average occupancy for a passenger vehicle is assumed to be 1.13 persons per vehicle, based on the 2009 National Household Travel Survey [6]. For a PRT vehicle, there are usually two to four occupants [4]. Fuel consumption impacts are analyzed under different PRT occupancy scenarios.

- VMT distribution and fuel consumption: The VMT distribution by vehicle age and vehicle type, as well as fuel consumption data by speed, vehicle age and vehicle type, are required. The analysis utilized a set of fleet average fuel consumption data that are based on a realworld fuel consumption study conducted by the University of California-Riverside [7]. The fuel consumption study and the PRT mobility study were conducted in 2005 and 2003 respectively; therefore, the fuel consumption data are suitable to be applied for the fuel consumption analysis. Although the fuel consumption data were based on an average vehicle fleet in southern California, which is different than the location of the mobility study, it remains valid as a comparative analysis for before and after impacts of an AMD. The University of CaliforniaRiverside study estimated speed-dependent fuel consumption for an average vehicle at real-world driving and steady-state driving conditions. The fuel consumption data at real-world driving are applied to VMT from vehicles driving on a road network to estimate the fuel consumption (including VMT from parking lots), and fuel consumption under steady-state driving condition is applied to PRT system vehicle. Steady-state conditions are used in this study because PRT vehicles run on a guideway which avoids the influence of other vehicles and pedestrians so that they can run at a steady speed between stations (see Fig. 3). This is admittedly a simplified assumption, however note that PRT and for that matter AMD vehicles could be substantially downsized relative to average vehicles and as such achieve much greater fuel efficiency. 
- Fuel consumption benefits of steady-state driving: For an average speed of $30 \mathrm{mph}$, the steady-state fuel consumption is 2.78 gallons per 100 miles versus realworld driving at 3.86 gallons per 100 miles for an average vehicle, according to the University of California study [7]. This equates to $30 \%$ fuel consumption and $\mathrm{GHG}$ emissions benefit for $30 \mathrm{mph}$ driving (assumed for the PRT or AMD vehicles).

- Fuel type of PRT: The initial analysis assumes PRT vehicles are powered by gasoline combustion engines. Although PRT can also be a hybrid electric vehicle or fully electric vehicle (which is most typical of operating and designed PRT systems), the fuel consumption benefits based on assuming a gasoline combustion engine can be considered as the lower bound of the benefits. Using any other type of drivetrain will increase the benefit. This framework is driven by the need to analyze the range of impact for an AMD based on AV technology and the factors that may enhance or degrade any benefits.

\section{RESUlTS AND DISCUSSION}

The total system fuel consumption and GHG emissions under different PRT operations as well as PRT average occupancy scenarios are presented in Fig. 4 and Fig. 5, assuming PRT vehicles are running on gasoline engines and the empty VMT factor equals 1.0 (conservative assumptions). The major observations and findings from these figures are summarized as follows:

1) As can be seen in Fig. 4 and Fig. 5, the fuel consumption and GHG emissions from personal vehicles in parking lots are the second largest contributor (though the aforementioned assumption attributing all parking lot time to vehicle circulation likely inflates its relative magnitude somewhat). Vehicles on the road network represent the largest contributor to fuel consumption and GHG emissions within the study area.

2) Fuel consumed by personal vehicles is reduced as PRT operates with less boarding time delay. This is simply because less PRT boarding delay leads to more people shifting from driving directly to campus to driving (or walking) to a PRT station and taking a PRT vehicle to campus. For the same reason, the fuel consumption by PRT vehicles increases as the average delay time decreases. These findings are consistent with those suggested by Table 2 and Table 3 .

3) Total fuel consumption and GHG emissions of the combined system decrease as the PRT delay time decreases, as more personal vehicle PMT are supplanted by PRT PMT. Also, as the occupancy of the PRT increases, energy and emissions further decrease due to reduced total PRT VMT.

4) As shown in Fig. 6 and Fig. 7, decreasing the empty-VMT factor to 0.5 also reduces total PRT VMT, and correspondingly, fuel consumption and GHG emissions.

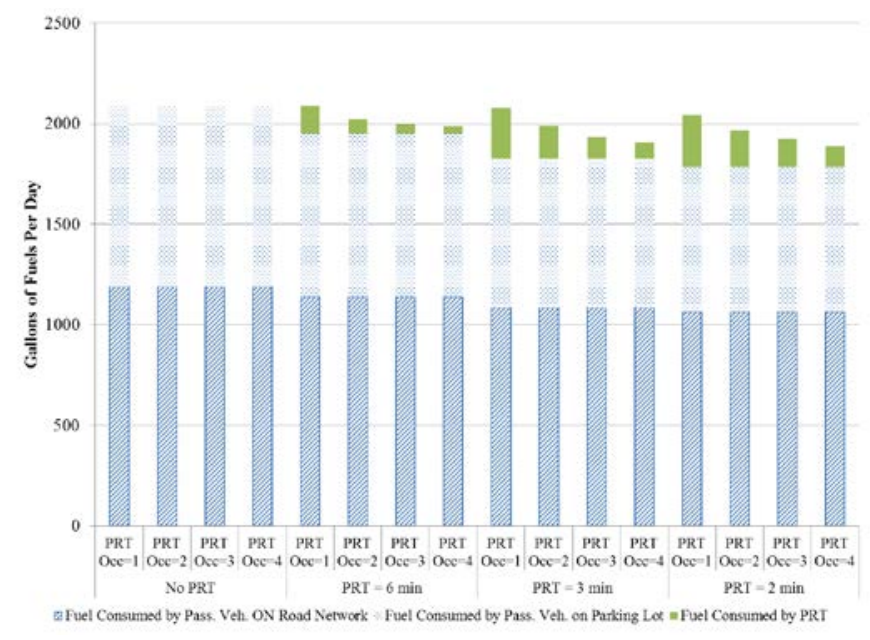

Fig. 4. Total vehicle fuel consumption within the study area under various PRT operation and occupancy scenarios, assuming the empty-VMT factor is 1.0 .

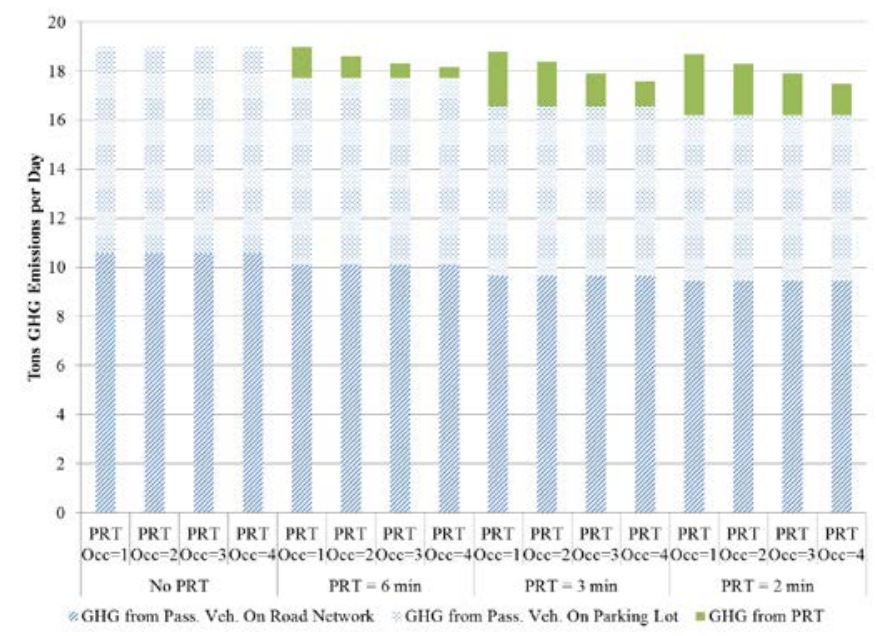

Fig. 5. Total vehicle GHG emissions within the study area under various PRT operation and occupancy scenarios, assuming the empty-VMT factor is 1.0. 


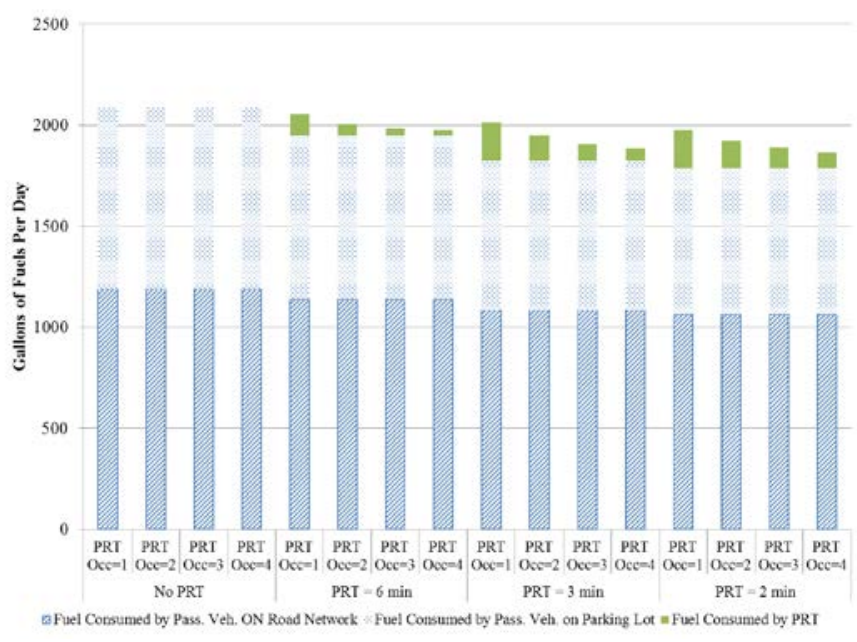

Fig. 6. Total vehicle fuel consumption within the study area under various PRT operation and occupancy scenarios, assuming the empty-VMT factor is 0.5 .

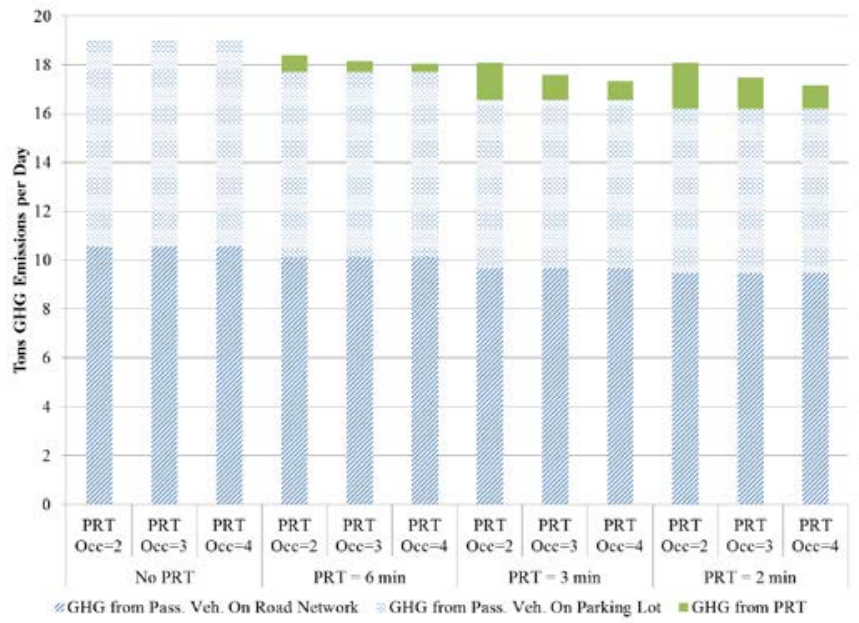

Fig. 7. Total vehicle GHG emissions within the study area under various PRT operation and occupancy scenarios, assuming the empty-VMT factor is 0.5 .

As evidenced by the PRT systems currently in service, PRT (or AMD) vehicles operating within a defined area may more likely operate using electricity than gasoline. For the most optimistic scenario of fully electric PRT vehicles powered by renewably-generated electricity, the green bars in Fig. 4 through Fig. 7 could be discarded (leaving just the contribution of personal vehicles to overall fuel consumption and GHG emissions).

As previously discussed, the baseline results for this study assumed a $30 \%$ reduction in the fuel consumption and GHG emissions rates for PRT vehicles relative to conventional passenger vehicles. Other recent studies have suggested even higher possible levels of efficiency benefits from AV features, with some estimates as high as a $90 \%$ improvement over conventional vehicles [8]. Therefore, a sensitivity analysis was conducted to understand the influences of PRT (or AMD) vehicles' fuel consumption improvements to system-level fuel consumption (Fig. 8). The potential for reduction in the PRT vehicles' fuel use ranged from $30 \%$ to $90 \%$. In all scenarios, total system fuel consumption decreases as the PRT vehicle's fuel efficiency improves. However, the marginal reduction in total system fuel consumption by reduced PRT vehicle's fuel consumption is higher for a PRT operating at 2- or 3-minute delay time than at a 6 -minute delay. The same observation holds for GHG emission reduction.

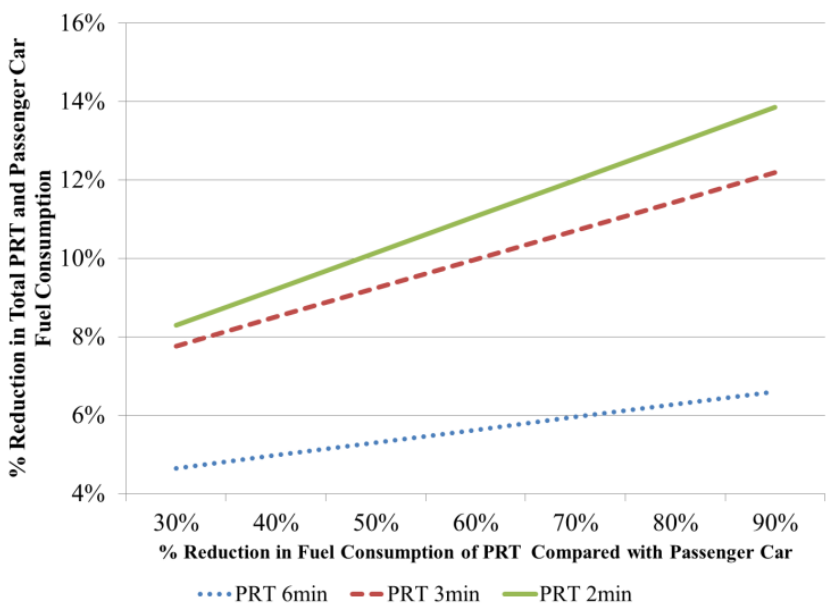

Fig. 8. Reduction of total system fuel consumption under different PRT operating and fuel efficiency scenarios, assuming average PRT occupancy at three riders per ride and empty PRT VMT factor at 0.5.

\section{CONCLUSIONS AND DISCUSSION}

With emerging AV technologies, travel behavior may change significantly, shifting PMT away from personal vehicles to systems such as AMDs. The impact on energy and GHG emissions is determined by multiple factors, including the relative efficiency of the vehicles, the occupancy of vehicles within the AMD, and the ratio of supplanted VMT.

The modeled PRT system has the potential to reduce fuel and GHG emissions, reflecting the general impact that an AVbased AMD system may have. As no AMD has been deployed based on AV technology, studies of PRT systems may serve as a surrogate because they share many commonalities, differing primarily in the use of dedicated guideways. The PRT system studied on the campus of KSU supplants a portion of the personal VMT in the campus central area, which is usually highly congested, with travel on the PRT system. The ratio of induced PMT on the PRT to supplanted personal vehicle miles ranges from 1.45 to 1.71 , depending on passenger delay of the PRT system.

Even with the increase in travel demand, the PRT system has the potential to reduce system fuel consumption based on higher occupancy and better vehicle performance. However, both of these parameters are derived from data or assumptions external to the original study. Assumptions of increased PRT vehicle efficiency are defensible based both on significant research and data on fully electric vehicles, as well as existing deployment of fully electric vehicle PRT systems. In contrast, PRT vehicle occupancy as well as empty-vehicle circulation factors have little supporting data. Although PRT systems are in operation, none are of the scale that reflects an AMD. As the results are highly sensitive to occupancy and re-circulation parameters, future research is needed to address these areas of uncertainty. Future research recommendations include a PRT/AMD modeling and simulation framework capable of capturing vehicle occupancy and empty vehicle recirculation characteristics. 
The analysis showed the potential to reduce vehicle fuel consumption and GHG emissions $4 \%$ to $14 \%$ in the study area based only on resolving intra-campus mobility issues. The model does not address other opportunities enabled by a functional AMD, namely the potential to increase transit and ride-sharing to access the campus. Future research should expand the geographic scope to include such impacts.

\section{ACKNOWLEDGMENT}

This work was supported by an internal LaboratoryDirected Research and Development project at NREL.

\section{REFERENCES}

[1] NHTSA, 2013. "Provides guidance to states permitting testing of emerging vehicle technology," National Highway Traffic Safety Administration, NHTSA 14-13, 30May.

http://www.nhtsa.gov/About+NHTSA/Press+Releases/ci. U.S.+Department + of + Transportation + Releases + Policy $+\mathrm{o}$ $\underline{n}+$ Automated+Vehicle+Development.print accessed 26 October 2014.

[2] IHS, 2014. Emerging Technologies: Autonomous CarsNot If, But When, Automotive Technology Research, IHS Automotive, 2 January. http://press.ihs.com/pressrelease/automotive/self-driving-cars-moving-industrysdrivers-seat; download PDF at http://orfe.princeton.edu/ alaink/SmartDrivingCars/PDFs/ IHS\%20 EmergingTechnologies AutonomousCars.pdf accessed 19 September 2014.

[3] S. E. Young, R. Miller, and E. D. Landman, "Travel demand modeling of automated small vehicle transit on a university campus," Proceedings of the 2003 MidContinent Transportation Research Symposium, 2003.

[4] W. He, E. D. Landman, and E. R. Russell, Assessment of a personal rapid transit system within a university campus and surrounding community, Kansas Department of Transportation; Report K-TRAN:KSU-02-7, 2005.

[5] Advanced Transit Association, 1988. "Personal rapid transit (PRT): Another option for urban transit?" J. Adv. Transport., vol. 2, no. 3, pp. 192-314.

[6] A. Santos, N. McGuckin, H. Y. Nakamoto, D. Gray, and S. Liss, "Summary of travel trends: 2009 National Household Travel Survey," Federal Highway Administration, Report FHWA-PL-11-02, Washington D.C., June 2011.

[7] M. Barth and K. Boriboonsomsin, "Real-world carbon dioxide impacts of traffic congestion," Transportation Research Record: Journal of the Transportation Research Board, No. 2058. Transportation Research Board of the National Academies, Washington, D.C., 2008, pp. 163171.

[8] J. Greenblatt and S. Saxena, "Autonomous taxis could greatly reduce greenhouse-gas emissions of US light-duty vehicles," Nature Climate Change, Vol. 5, pp. 860-863, 2015. doi:10.1038/nclimate2685. 